\title{
Core Elements Underlying Supply Chain Management in the Construction Industry: A Systematic Literature Review
}

\author{
Walter Puppo Studer * and Luiz Carlos Brasil De Brito Mello \\ Escola de Engenharia, Universidade Federal Fluminense, Niterói 24210-240, Brazil; luiz_brasil@id.uff.br \\ * Correspondence: wpuppo@id.uff.br
}

Citation: Studer, W.P.; De Brito

Mello, L.C.B. Core Elements

Underlying Supply Chain

Management in the Construction Industry: A Systematic Literature Review. Buildings 2021, 11, 569. https://doi.org/10.3390/

buildings11120569

Academic Editor: Audrius Banaitis

Received: 19 October 2021

Accepted: 16 November 2021

Published: 23 November 2021

Publisher's Note: MDPI stays neutral with regard to jurisdictional claims in published maps and institutional affiliations.

Copyright: (c) 2021 by the authors. Licensee MDPI, Basel, Switzerland. This article is an open access article distributed under the terms and conditions of the Creative Commons Attribution (CC BY) license (https:// creativecommons.org/licenses/by/ $4.0 /)$.

\begin{abstract}
The relevance of supply chain management (SCM) is being increasingly recognized in the construction industry. However, its implementation has been limited and is still challenging for researchers and practitioners. An adequate and systematic understanding of context-specific core concepts and practices are considered fundamental to foster its implementation. This paper aims to provide a holistic look into the existing research on elements underlying SCM in the construction industry. It adopts a systematic literature review method to examine almost two decades of publications and uses a comprehensive SCM framework to synthesize the findings. The results revealed a set of 19 core elements clustered in five subject areas (i.e., 'strategic management', 'logistics', 'relationships', 'best practices' and 'organizational behavior') that have a prominent role in construction SCM. Every core element was analyzed in detail and the results were discussed in the context of other evidence. This study produced the first comprehensive picture of the current state of knowledge, providing relevant contributions to enhance the understanding and implementation of SCM within the construction industry.
\end{abstract}

Keywords: construction industry; SCM; strategic management; logistics; relationships; best practices; organizational behavior

\section{Introduction}

Construction supply chains (CSCs) involve all construction processes, from the initial demands, design and construction to maintenance, replacement and eventual demolition of buildings and other structures [1]. Every year, about USD 10 trillion are spent on construction-related goods and services, equivalent to $13 \%$ of the world's GDP, employing $7 \%$ of the world's working population. Thus, construction is one of the largest sectors of the world economy [2]. In spite of being an important contributor to the global economy and playing an important role in economic development, it is a complex sector, which is facing difficulties and challenges all over the world $[3,4]$.

The construction industry has been widely criticized for a marked tendency to generate waste and for its inefficiency [5], low-profit margin [3], low productivity [6,7], frequent schedule delays, cost overruns and quality defects [8-10]. According to Behera et al. [9], a major part of these problems can be traced to the interfaces of different parties involved in construction supply chains. A myopic and independent control of construction supply chains [1], exacerbated by characteristics such as fragmentation [11,12], lack of coordination and communication between participants [13], adversarial short-term relationships [14], separation of design and construction [1] and mistrust [6] is causing performance-related problems.

Since the 1990s and in response to perceived recurrent problems, there has been a growing interest in supply chain management (SCM) practices to improve the construction industry performance $[15,16]$. The recognition of the fact that the competitiveness of an isolated organization critically depends on the supply chain (SC) dynamics in which it participates led to re-examine relationships and interdependencies among supply chain 
partners [8], and various government reports and initiatives concurrently suggested that the construction industry would benefit from adopting more collaborative forms of working [17]. Incorporating some of the lessons learnt from other sectors, SCM was considered for adoption in the construction industry. The improvements that can be obtained with such an approach are increasingly being recognized throughout the industry community $[15,18,19]$.

Notwithstanding, while other industries such as manufacturing and retailing have made significant performance improvement by adopting supply chain management [18], achieving more closely integrated and efficient supply chains [14], the construction industry seems to be facing difficulties in implementing SCM $[7,14,20]$. Several studies indicate that challenges mostly originate from the fundamental differences between these industries [21]. While manufacturing supply chains are based on continuous processes and relationships [15], construction supply chains involve a multitude of stakeholders [22] in temporary sites and temporary organizational configurations [23]. A typical CSC is a long [8] and complex [18] network of numerous organizations (i.e., clients/owners, designers, general contractors, subcontractors and suppliers) and relationships [22], connected through the flows of information, the flows of materials, services and products and the flows of funds [6] (see Figure 1). Almost every CSC is unique, non-repeatable and established just for fulfilling the requirements of a single project [24]. Furthermore, production sites are not controlled environments, being prone to high variability and unpredictability (e.g., changing weather conditions) [25]. All these factors contribute to unique levels of uncertainty and instability that jeopardize a direct transfer and application of SCM models developed for other contexts to the construction industry [10,13,15]. At the same time, while SCM concepts have been extensively researched in other industries [10], knowledge about SCM in the construction industry is still embryonic and research in this topic is relatively limited $[9,18,26]$. To introduce SCM successfully without being "lost in translation", numerous researchers advocate for further scrutiny and proper understanding of core concepts and practices underpinning SCM in the construction industry $[9,13,20,23]$.

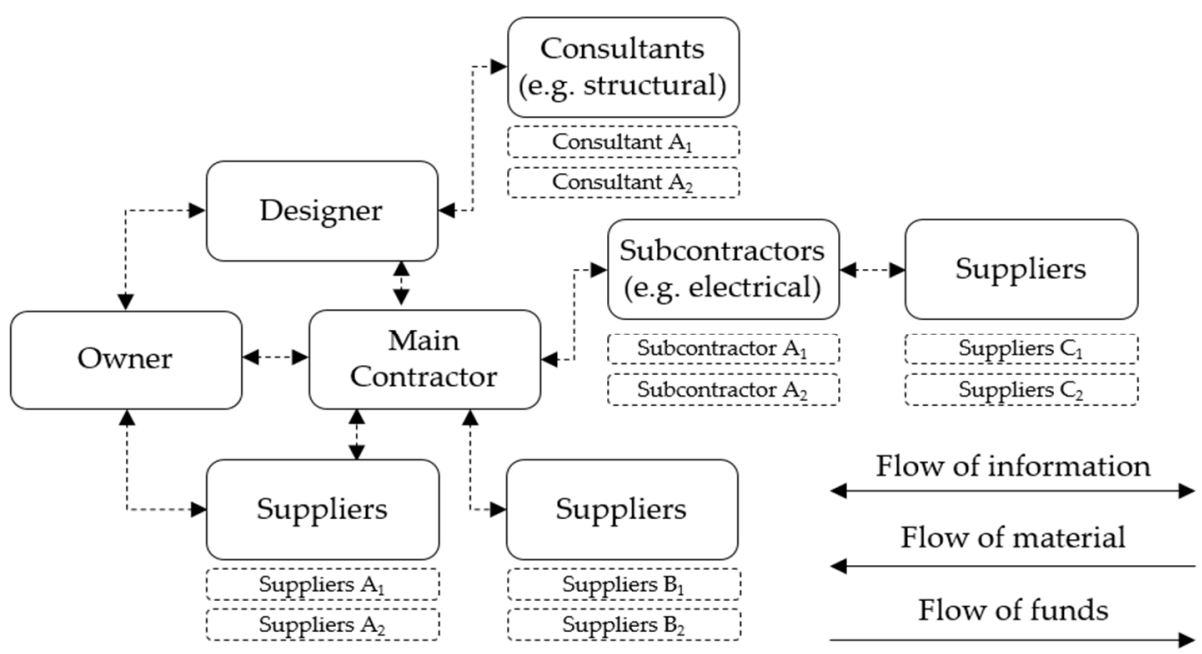

Figure 1. A typical construction supply chain. Adapted from [22].

Supply chain management is, indeed, an extremely complex and diverse discipline, as reflected in the broad range of diverse suggested definitions [16]. It is an evolving field that encompasses different perspectives and contributions from distinct fields of research [27]. Its development was initially along the lines of logistics [27], but additional concepts and practices from social and organizational sciences (e.g., collaboration between partners) have been gradually incorporated into the body of knowledge [28]. Tiwari et al. [26] carried out a literature survey to analyze the existing state of research relating to SCM in construction. They showed that researchers were keen on developing and pursuing various decision-making models and exploring areas such as supply chain integration and 
coordination. Other areas explored by scholars are the emphasis on material flows and information flows and the feasibility of SCM application in particular geographical regions such as Europe, Asia and Oceania. Despite these contributions, their study also revealed that most studies focus on understanding very specific areas and are short of offering a comprehensive solution. Consequently, there is a clear dearth of research, which takes a holistic approach to SCM in construction [17].

Based on this research gap, the present study reviews the documented evidence of SCM elements in the construction industry. We drew a comprehensive picture of current knowledge, capturing the full range of perspectives and contributions incorporated from distinct fields of research. The formal review question guiding this process was: 'What are the documented core elements that support supply chain management in the construction industry?' More specifically, the objectives of this study were:

- Extract from the existing research the documented core elements underpinning SCM in the construction industry;

- Provide a structured and comprehensive picture of the current state of knowledge of SCM in the construction industry;

- Analyze the extracted elements through the lens of a holistic SCM framework to gain an overview and proper understanding of construction SCM core concepts and practices.

The remainder of this paper reflects these objectives and is structured as follows: Section 2 describes the methodology employed for the systematic literature review. Section 3 presents a descriptive analysis of the selected articles and our findings, organized by the subject areas of the framework. Next, Section 4 provides a general interpretation of the results in the context of other evidence. Finally, Section 5 offers the concluding remarks, including contributions, limitations of the study and opportunities for future research.

\section{Materials and Methods}

The methodology employed in this study was a systematic literature review (SLR), which is a "specific methodology that locates existing studies, selects and evaluates contributions, analyses and synthesizes data, and reports the evidence in such a way that allows reasonably clear conclusions to be reached about what is and is not known" [29] (p. 671). Being first introduced in the medical sciences research, the systematic approach plays a fundamental role for knowledge advancement in many fields and is spreading significantly in the supply chain management domain [30]. Conducting an SLR requires following a sophisticated protocol to ensure a more comprehensive and unbiased search is performed, with transparent, reliable and reproducible findings [31,32]. The implementation of this protocol is summarized below.

\subsection{Systematic Review Protocol}

ISI Web of Science (https: / clarivate.com, accessed on 18 April 2020) was chosen as the database for the present literature search. It is a trustful database that contains the top journals in the general management and engineering fields, hence ensuring a broader diversification of credible studies. To screen papers by content, different search queries were tested before defining the final parameters. First, brainstorming was used to select keywords related to concepts and practices. Then, by applying the snowballing technique to a preliminary screening of records, new keywords were added. Finally, the selected keywords were combined with the terms 'supply chain management' and 'construction' to build the following search string: (("supply chain management") AND construction AND (action OR activity OR antecedent OR approach OR aspect OR concept OR discipline OR element OR factor OR feature OR practice OR pre-condition OR prerequisite OR principle OR procedure OR tactic OR technique OR tool)). This search string was entered into the topic field, which performed the search in the title, abstract and keywords of the source, yielding 554 results. 
The results were then evaluated following a set of classification criteria, as summarized in the PRISMA flow diagram [33] presented in Figure 2. The first classification criteria limited the search to peer-reviewed journal papers written in English and published until December 2019. Therefore, proceedings papers, reviews and editorial material were excluded as well as papers written in German, Japanese, Russian and Spanish, leaving a sample with 321 articles.

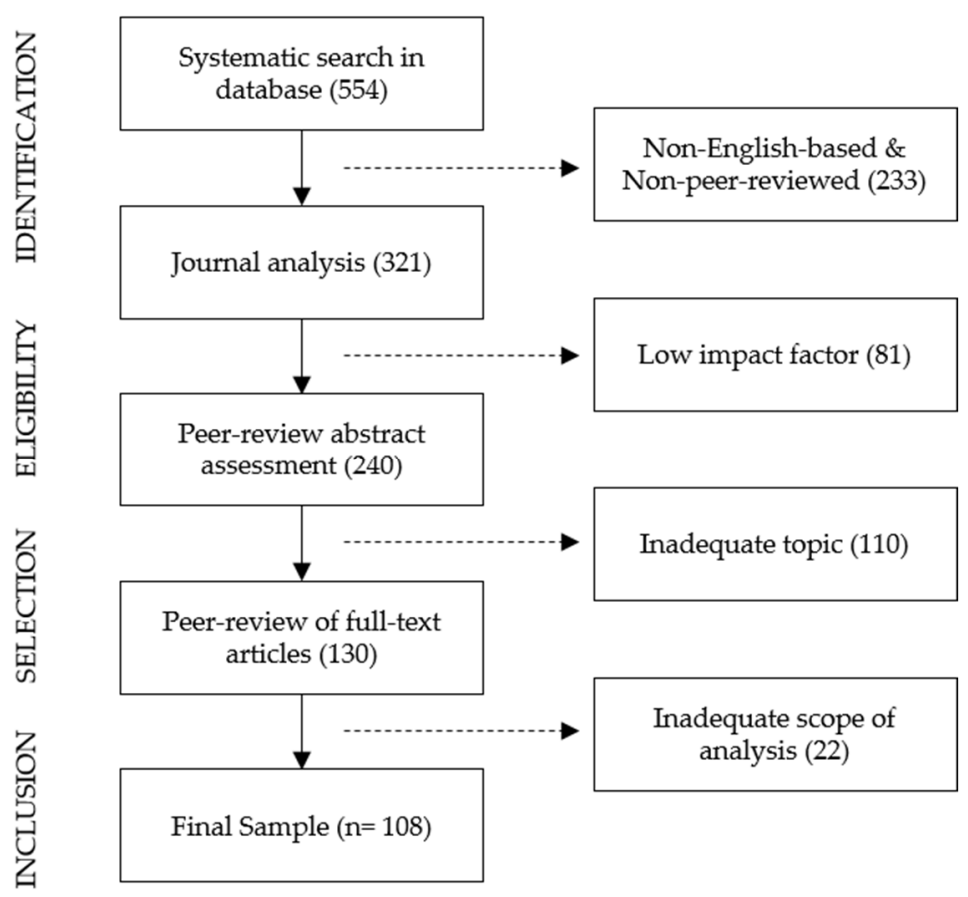

Figure 2. Study selection and evaluation. Based on the PRISMA flow diagram, with permission of Moher et al. [33]; published by PLOS Medicine, 2009.

The following classification criteria was a quality assessment, where only the papers of journals with impact factor, based on the Thomson Reuters listing, were included. This reduced the sample to 240 articles. Following this, the abstracts of papers that passed this stage were read and, in order to avoid researcher bias [31], subjected to a two-part selection filter, downsizing the sample to 130 articles. First, the main author conducted an examination of the abstracts, excluding some reports, and then the second author confirmed the selection and double-checked the borderline cases. The excluded papers were not specific for the construction industry, mentioned construction with another meaning (e.g., 'sample construction' and 'construction of pairwise comparison') or were perceived as not relevant to the research question (i.e., not discussing CSCM-underlying elements).

The final classification criterion was an in-depth full-text review, which led to the exclusion of 22 papers. The exclusion criteria consisted of articles mentioning CSCM underlying elements as a background for discussing other main issues or articles only focused on employing or developing mathematical methods, engineering modeling or simulations. Overall, 108 articles passed all stages of the protocol and formed the final sample to be further analyzed. Through a structured procedure, all 108 articles were classified in terms of authors, titles, years of publication, journals, countries of origin and major contributions.

\subsection{The Analytical Framework Used to Synthesise and Interpret the Findings}

Qualitative approaches to synthesize the evidence extracted through systematic reviews tend to be particularly relevant for management sciences, principally due to the divergent nature of the discipline [32]. This approach enables the identification of themes among different studies to attain a greater level of conceptual or theoretical development [31]. In 
the present review, we have chosen Croom et al.'s [27] supply chain management analytical framework as the conceptual tool for coding and synthesizing the findings.

After conducting a critical literature review based on the analysis of a large number of publications on supply chain management (i.e., books, journal articles and conference papers), Croom et al. [27] presented a framework for categorizing the SCM linked literature. According to the authors, it provides a taxonomy with which to map and evaluate research, allowing its classification in the field as well as enabling the identification of key content of the subject. Therefore, Croom et al.'s [27] framework was considered appropriate as an a priori-defined coding structure for our analysis.

The following procedure was implemented. The first author manually coded the extracted elements into the subject areas defined in Croom et al.'s [27] framework. Decisions were iteratively checked, ensuring coding reliability. Then, the second author doublechecked the codes against both the original data and the framework subjects. Eventual disagreements were debated until resolved, thus minimizing errors, and producing a more robust structure of findings.

\section{Findings}

\subsection{Descriptive Analysis of the Sample}

The descriptive analysis of the 108 sources presented in Figure 3 shows the rising rate in the number of articles published per year and, more specifically, the pronounced increase of publications over the last few years. Among all the selected papers, $81 \%$ of them were published since 2010, and $56 \%$ of them were published in the last 4 years, indicating the growing attention that the review subject has received from researchers.

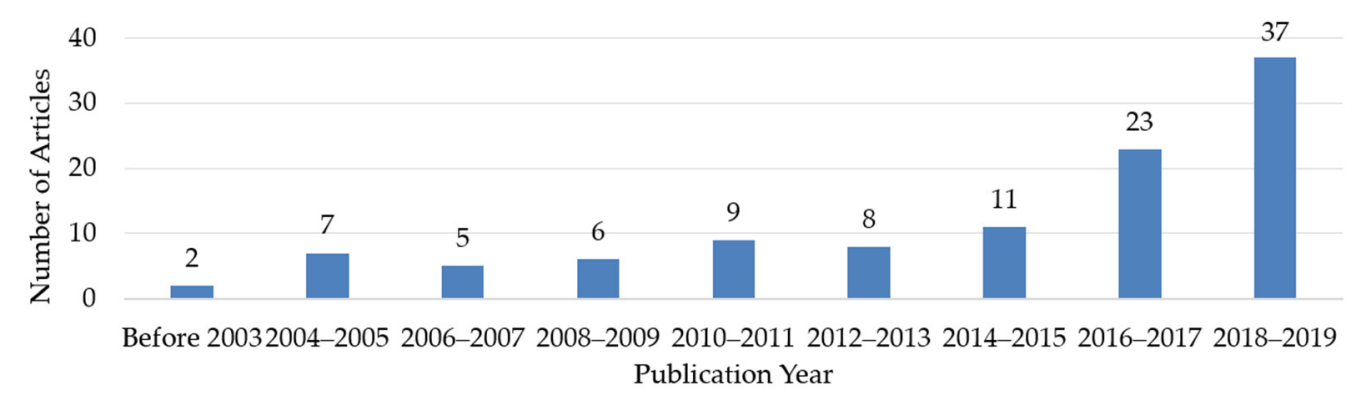

Figure 3. Distribution of selected articles by publication year.

This review confirmed how construction SCM literature is scattered across different journals and research areas. The selected papers were published in 42 different journals that cover 10 research areas. Even though five journals included $45 \%$ of the papers, almost $80 \%$ of the journals were only being represented by a maximum of two papers. The three most representative subject areas are engineering, business and economics and construction and building technology, accounting for almost $70 \%$ of the sample (see Figure 4 ).

Moreover, the distribution analysis of the selected papers according to the geographical location of the first author's research institution highlights the spread of papers across various locations. Thirty countries from six different continents contributed to this review. Figure 5 shows that Europe, Asia and Oceania, which altogether accounted for almost $88 \%$ of the total number of collected papers, were the major sources of information on the subject, confirming the regional differences in research appointed by Tiwari et al. [26]. When analyzed by country, the top three contributors were China, England and Australia, with $18 \%, 12 \%$ and $11 \%$ of the papers published, respectively. 


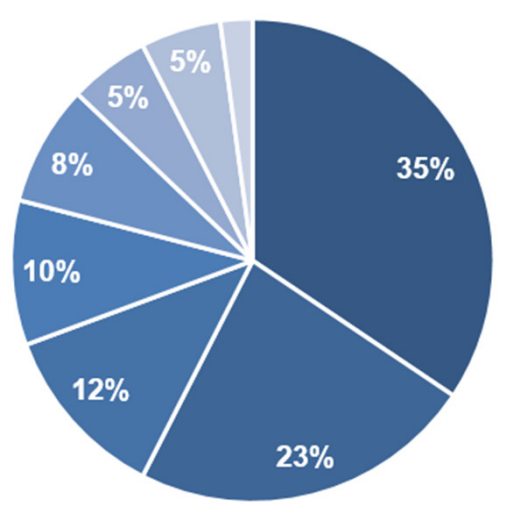

- Engineering

- Business \& Economics

- Construction \& Building Technology

- Science \& Technology - Other Topics

- Environmental Sciences \& Ecology

- Computer Science

- Operations Research \& Management Science

- Others (Transportation, Mathematics, Automation \& Control Systems)

Figure 4. Research areas of journals. Note: Some journals cover more than one research area.

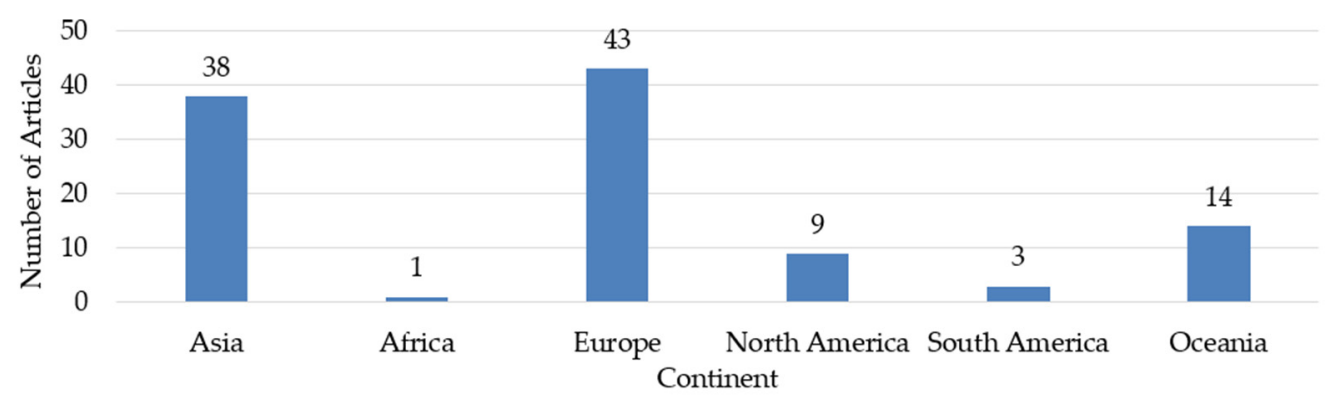

Figure 5. Distribution of the selected articles by the continent of the first author's research institution.

The descriptive analysis of this work also performed a comprehensive keywords co-occurrence network using the VOSviewer tool. According to [34], keywords are a clear and concise way to describe research contents. A network map of keywords facilitates the visualization of the knowledge structure of a particular field of research, unveils emerging elements and depicts the dynamics of the knowledge structure. Therefore, a keywords co-occurrence network was generated setting the minimum number of occurrences to five, as shown in Figure 6.

The frequency of occurrence of the keywords and their interconnections can be denoted according to node sizes, the distance among nodes and connection lines among keywords [35]. The size of a node is a depiction of its weight in the network, while the distance among nodes represents their relatedness. The closer the nodes are, the stronger the connection between them. Items with the same color represent an identical cluster, meaning that keywords within the same cluster are more closely linked to each other [35]. Accordingly, as can be seen in Figure 6, four different clusters were generated. With ten keywords each, the most important clusters were the red and the green ones, which focused on the logistics and the relationships component bodies, respectively. The blue cluster represented the strategic management component, containing keywords such as 'management', 'framework' and 'system'. Lastly, the yellow cluster reminded us of the importance of sustainability to the construction supply chain. The keywords co-occurrence network showed that these are the principal component bodies of SCM literature in the construction industry. 


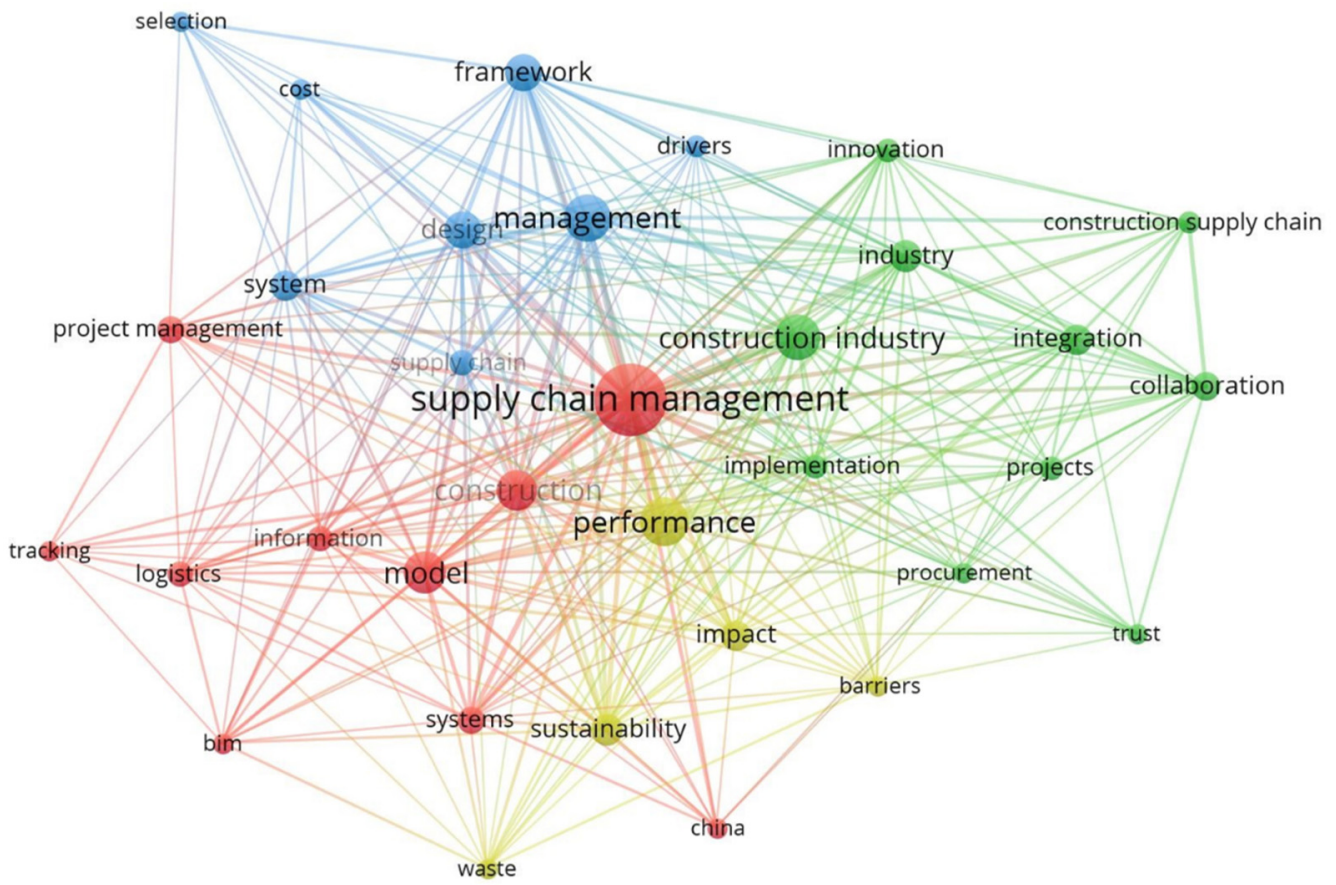

Figure 6. Network of co-occurrence of keywords from the selected papers.

\subsection{Core Elements Underpinning SCM in the Construction Industry}

The presentation of thematic findings is based on Croom et al.'s [27] framework, that distinguish six subject areas related to the field of supply chain management: 'strategic management', 'logistics', 'marketing', 'relationships', 'best practices' and 'organizational behavior'. The framework also identifies and classifies the concerns within each subject area, thus providing specific guidance for categorizing core elements. The review of findings in this section follows this structure. A set of 19 core elements, identified in at least three papers, were extracted from the reviewed literature and classified into five SCM subject areas. The next sections provide a description of each topic, organized by the subject areas of Croom et al.'s [27] framework, and the full list of results can be found in Table 1. Four of the five subject areas identified (i.e., 'strategic management', 'logistics', 'relationships' and 'best practices') are strongly correlated with the four principal component bodies unveiled by the keywords co-occurrence network (see Figure 6), validating the suitability of the selected framework to synthesize the findings. The remaining subject area, 'organizational behavior', is also included in the keywords co-occurrence network, but appears integrated into the 'logistics' component body.

Table 1. Core elements underlying construction supply chain management.

\begin{tabular}{|c|c|c|}
\hline Subject Area & Element & References \\
\hline Strategic Management & $\begin{array}{c}\text { Global strategy } \\
\text { Change management } \\
\text { Capacity development }\end{array}$ & $\begin{array}{c}{[8,20,23,36-41]} \\
{[38,40-44]} \\
{[11,20,23,40,42,45,46]}\end{array}$ \\
\hline Logistics & $\begin{array}{l}\text { Planning and control of material flows } \\
\text { Integration of materials and information flows }\end{array}$ & $\begin{array}{c}{[3,21,25,47-56]} \\
{[19,21,57-61]}\end{array}$ \\
\hline Relationships & $\begin{array}{c}\text { Procurement } \\
\text { Objectives alignment } \\
\text { Top management support and long-term } \\
\text { commitment } \\
\text { Trust } \\
\text { Collaboration } \\
\text { Communication } \\
\text { Problem solving } \\
\text { Risk sharing }\end{array}$ & $\begin{array}{c}{[3,6,7,17,18,20,24,36,39,50,62-70]} \\
{[10,16-18,20,38]} \\
{[10,11,18,20]} \\
{[5,7,10,18,20,23,71-73]} \\
{[1,5-7,9-11,13,14,16-18,20,23,28,38,39,41,74-79]} \\
{[10,11,14,16-18,20,21,23,28,74,80-82]} \\
{[10,14,18]} \\
{[10,18,20,24,44,83-86]}\end{array}$ \\
\hline
\end{tabular}


Table 1. Cont.

\begin{tabular}{ccc}
\hline Subject Area & Element & References \\
& Continuous improvement & Lean thinking \\
Best Practices & Just-in-time & {$[9-11,14,16-18,20,23,37,38,62,87-89]$} \\
& Offsite manufacturing & {$[15,66,75,90,91]$} \\
& Sustainability & {$[15,41,92,93]$} \\
Organizational & Information and Communication Technology & {$[4,15,51,54,57,66,89,93,94]$} \\
Behavior & (ICT) Integration & {$[16,40,43,45,46,49,64,70,81,95-114]$} \\
\hline
\end{tabular}

It should be noted that although a certain level of overlapping may exist among the elements, this is a common feature in the SCM literature, where plenty of overlapping terminology and meanings exist [27]. Moreover, the holistic view of Croom et al.'s [27] framework makes core elements definition less specific, and each core element may include several related aspects. For example, the core element 'planning and control of material flows' include aspects such as supply network design, materials buffers definition and project scheduling, among others. Two additional matters regarding elements classification are worth mentioning. First, as certain topics can be approached from multiple perspectives, they could be classified in more than one subject area. This was the case of 'just-in-time', which was classified in favor of 'best practices' rather than 'logistics', and 'communication', classified in 'relationships' rather than 'organizational behavior'. Both choices were based on the analyzed literature prevalent criteria. Additionally, 'sustainability' and 'off site manufacturing', not included as concerns in Croom et al.'s [27] framework, were classified in the 'best practices' field.

\subsubsection{Strategic Management}

This subject area comprises three elements, namely, 'global strategy', 'change management' and 'capability development'. Supply chains are networks of independent but collaborating entities, where the performance of each of them depends on the performance of their partners [36]. Therefore, a global strategy pointing towards an emphasis on holistic systems is required to pursue competitive advantage. It should properly specify the participating entities and the relationships among them to achieve high value generation [37,38], extending its scope to reach participants many layers up and down in the SC tiers [39]. This is not an easy task, especially considering the large number of participants working together in a project-based temporary manner [37]. However, as supply chains are becoming increasingly dependent on small- and medium-sized enterprises, which perform most project activities [20,39], a global strategy is essential to create the conditions and enhance the possibilities of successful SCM implementation [23].

A strategic change management approach is recommended to face the conservative nature of the industry. Organizations ought to show a willingness to change their culture, structure and processes [42]. To this end, strategies should focus on the dissatisfaction with the status quo, highlighting the need for transformational change and sensitizing organizations to the benefits that SCM offer both to themselves and their SC [40]. Communicating and convincing staff about what the change is and why it is happening, coupled with top management support [43] and the figure of a change champion [42], are essential tools to overcome resistance. In addition to the motivation, there is a need to promote a proper understanding of the concepts underlying SCM [23] and develop the competencies required to work with them [42]. This entails mobilizing and educate key SC stakeholders, providing training programs to employees at all organizational levels $[40,45]$ and active guidance in the practical context [42]. Such approaches, aimed at the development of knowledge, competencies and experience, are critical to achieve goals and contribute to both short-term and long-term success [20]. 


\subsubsection{Logistics}

The two elements included in this subject area are 'planning and control of material flows' and 'integration of materials and information flows'. Transport and logistics of construction materials represent an important share of total costs [118]. Inefficiencies in the planning and control of material flows, such as late deliveries, incomplete orders and quality deficiencies, result in the disruption of construction processes, causing delays and increased costs [47]. Even thoguh time and material buffers are commonly used to mitigate these risks, they may contribute to significant time waste and enormous additional costs $[3,21]$. Therefore, planning and control of material flows, involving the mechanisms to ensure the availability of materials at the right time, with the required quantity and minimum cost [48], are critical to the success of a project. Accordingly, many models to support decision making for tasks, such as selection of material sources, determination of the number of deliveries and project scheduling, have been proposed by researchers [49-54]. Moreover, studies indicate efficiency potentials in applying collaborative supply networks $[47,55]$. In the traditional practice, each actor coordinates its own materials supply (i.e., storage, packaging and transport) and onsite logistics activities (i.e., material handling activities). An extended scope of coordination, considering joint coordination of materials supply and onsite logistics activities, or even coordination of activities beyond individual sites, including all supply chains directed to them, entails opportunities for improving performance [55].

The second element, integration of materials and information flows, is crucial for improving the visibility and traceability of materials throughout the construction supply chain. This is not only a way of reducing the uncertainties that affect the above-mentioned planning practices, but also supports progress monitoring and materials management processes as a whole [21,57]. Different technologies, such as radio frequency identification (RFID) [58,59], machine learning [60] and smart construction objects (i.e., construction resources augmented with sensing, processing and communication abilities) [61], have been proposed to improve the transparency of information. The central tenet underpinning these technologies is to increase the quantity, rate and quality of information. With accurate information available at the right time and in the right format, project managers can make prompt and informed decisions [59].

\subsubsection{Relationships}

Almost $43 \%$ of the elements belong to this subject area, which includes 'procurement', 'objectives alignment', 'top management support and long-term commitment', 'trust', 'collaboration', 'communication', 'problem solving' and 'risk sharing'. The strong competitive environment puts pressure on construction companies to concentrate on core competencies and provide their requirements by outsourcing [62]. Companies are becoming increasingly dependent on suppliers (i.e., material and equipment suppliers and service suppliers) [24], which have a lasting effect on the success of a project [63]. Hence, the evaluation and selection of the best-fit suppliers are of vital importance [62]. Traditional procurement, based on the lowest tendered price, does not necessarily result in a low actual cost nor a good project delivery [18], and limits the flexibility of suppliers to explore innovative solutions that could enhance performance [17]. A multi-criteria decision-making procurement approach is frequently applied to achieve the best value for a project [18,64]. It uses a set of weighted pre-qualification criteria to assess the resources and capabilities of suppliers [20], and those with the highest aggregate weighting are selected for further direct negotiation $[17,18]$. Pre-qualification criteria are a way to check the compatibility between the firms, and thus, it should be designed to reflect the unique entities of the relationship [39]. In addition to the evaluation and selection methodology, making early procurement decisions also has an important impact on project performance [65]. It not only allows suppliers to bring ideas to the design process and detect errors as early as possible, but also permits contractors to better plan construction processes [66]. 
Objectives alignment enable SC participants to work collectively in order to pursue common goals. Without objectives alignment, project actors' efforts may clash with one another or may not be compatible with the holistic project goals [17]. Therefore, mutual objectives should be established by maximizing mutual interests [18], nurturing a winwin scenario that will benefit everyone in the project [17]. Reaching a unified vision is a fundamental integrating mechanism that supports the creation of common a group identity and promotes active participation of partners [20], as all of them share responsibility for dealing with problems and maintaining relationships [10]. This full involvement of partners and the commitment to forming long-term relationships are essential ingredients for success [14]. Indeed, a long-term focus is fundamental to achieve the mutual benefits in SCM (e.g., improved quality and flexibility of operations), as it can provide higher value of cooperation and better exploration of knowledge [20]. As top managers are the ones who decide the business direction of an organization and the length of commitment to the supply chain, their support is of paramount importance for effective SC relationships [10].

Trust is an essential prerequisite to enable collaboration and co-prosperity between SC partners [7]. As defined by Li et al. [71], trust is the 'psychological expectation about the behavior of opponents or organizations'. In other words, it is about having the reliance and confidence that the trustee will do what is expected, with the expected standard, without intentionally harming the trustor [72]. Among the many factors that influence trust, Khalfan et al. [73] highlighted honest communication, reliance and delivery of outcomes. According to the authors, SC participants have to be open to share important information in an honest way and rely on each other compromises. Those who are more competent to deliver successfully the outcome of a project are more likely to be trusted. Building up mutual trust is necessary to modernize complex and highly fragmented CSCs [20]. Moreover, high levels of trust among SC participants allows decisive and flexible action in critical situations [5]. In an industry increasingly exposed to uncertainty, where unexpected problems are almost inevitable, trust liberates participants to pursue courses of action with confidence in each other's, enhancing greater agility, informality and morale in relationships [72].

Collaboration is the basis for good working relationships among participants and ensures supply chain efficiency and responsiveness [10]. It implies leaving behind adversarial relationships to embrace an integrated team culture [18], in which an emphasis on group effort prevails over individual efforts and rewards [6]. If things go wrong, energy is not wasted on looking for someone to blame. Instead, solutions are developed in a concurrent style [17]. In a collaborative supply chain, partners work together in an integrated and coordinated way in order to accomplish collective goals and to achieve mutual benefits [1]. This does not mean that relationships with every partner have to be collaborative, but efforts should focus on developing stronger ties with the more strategic ones and managing weaker ties through standardized practices [6]. The development of a more collaborative culture strongly depends on effective communication among SC partners, ensuring good and reliable flows of information [14]. However, under traditional contracts, there is often an unwillingness among SC participants to share information [21], affecting the formation of long-term relationships [10]. Information sharing reduces supply chain uncertainty and provides the possibility to anticipate situations [28], driving all the project phases and enabling correct and in time decision making [20]. An open and effective communication is crucial to obtain competitive advantages. It minimizes errors, reworks and schedule delays [10]. Additionally, it facilitates eliminating learning barriers, allowing participants to acquire knowledge, to innovate and to learn from the best business practices [74,80].

Conflicts among supply chain partners, which generally bring tension and lead to bad relationships, are hardly avoidable in the construction industry [10]. Therefore, early warning mechanisms should be established in order to anticipate potential problems. Furthermore, developing protocols for effective joint problem solving, continuous improvement and sharing learning mechanisms are essential not only to solve problems as early as possible but also to avoid the same problems to come again [14,18]. Unclear risk 
allocation is one of the roots problems of much litigation. Sharing risk and benefits is an SC commitment to share either profits or losses, being a motivation to achieve common goals [10]. A deep understanding of the key SC risks is pivotal to formulate more realistic plans and expectations. After estimating the impacts that they may cause on project objectives, partners can better allocate the risks through the entire supply chain [44]. Risks should be allocated to the parties who can best manage it, offering appropriate rewards. That is, return should be always be balanced against the effort [18].

\subsubsection{Best Practices}

Five elements are included in this subject area, i.e., 'continuous improvement', 'lean thinking', 'offsite manufacturing', 'just-in-time' and 'sustainability'. Continuous improvement refers to the continuous systematic planning and process development to achieve long-term performance improvement. It is not a one-off project initiative, and therefore, requires a joint effort of supply chain partners aiming to achieve the best value through long-term relationships [11]. Performance measurements are an important enabler of continuous improvement, making it possible to set some clear targets [87]. By comparing their performance against predefined goals, past performance or the 'best practice' performance, organizations can continuously learn and improve their processes [17], identifying the areas that need improvement and not adding value works that can be eliminated [10].

In this direction, lean thinking, a management approach influenced by the Toyota production system and widely recognized in many different industrial settings to improve supply chain performance, has been gradually adopted by the construction industry [15]. According to the Lean Enterprise Institute [119], its core objective is to maximize customer value while minimizing waste, considering waste as any effort that does not add value to the final product from the customer's point of view [75]. This includes material-related waste, to which the word waste predominantly refers in construction, but also waste associated with inputs such as workforce, time and equipment (e.g., activity start delays, rework, unused employee creativity, long approval process, etc.) [90]. The core principles of lean thinking within the construction industry include waste reduction, process focus in production planning and control, end customer focus, continuous improvements, cooperative relationships and systems perspective [15]. To implement them, the industry adopted lean tools and techniques from manufacturing, such as Value Stream Mapping and Six Sigma, but also developed specifically conceived methods, such as the Last Planner System [91]. Lean thinking proves to be important to improve project performance in terms of time, cost and quality. Moreover, when integrated with SCM, with supply chain partners collaborating with each other, the opportunities to minimize waste and maximize value are much greater [66].

Both offsite manufacturing and just-in-time are considered central practices for waste reduction in lean thinking [15]. Notwithstanding, these two practices have also attracted the attention of practitioners and researchers apart from the lean literature and are, therefore, discussed in detail. There are various terms associated with offsite manufacturing (OSM), such as prefabrication, preassembly and modularization [4]. In this paper, OMS refers to production systems in which standardized building components, elements or units are prefabricated in factory-based production environments before being shipped for subsequent onsite installation [51,66]. By moving traditionally onsite operations to areas under controlled conditions, OSM can lead to significant benefits such as construction time reduction, consistent quality, higher safety performance, improvements in constructability and a decrease in environmental impact [4]. However, shifting activities to remote locations also requires a higher level of integration among partners [57], such as manufacturing, transportation, inventory management and assembly sequences, which need to be carefully coordinated [51]. In this regard, just-in-time is a supply strategy that advocates smaller but more frequent deliveries to the construction site [15]. Its objective is to synchronize the delivery of materials with the assembly to minimize material buffers [41,92]. By doing this, just-in-time contributes to eliminating waste caused by overproduction, waiting time, 
transportation, stocks and second handling of materials, generating positive effects for both suppliers and contractors [93].

Sustainability, in its three-fold meaning (i.e., economic, environmental and social), is an increasingly important issue for the construction industry $[43,95,96]$. Environmental policies and customer concerns are stimulating the entire construction supply chain, a major contributor to environmental pollution, to adopt sustainability practices to minimize the negative consequences of project activities on environments while maximizing contribution to economics and society [97-100]. Sustainability practices can be distinguished between core and facilitating practices [45]. Core practices cover the major stages of the construction supply chain, including design, purchasing, transportation, construction and end-of-life management. These practices involve considerations such as the development of green building materials [101], prudent use of natural resources [16], the adoption of offsiteprefabrication [4], waste management planning [102,103] and reverse logistics [104,105], among many others. On the other hand, facilitating practices, which support core practices, consist of environmental management systems and certifications (e.g., policies, assessments, etc.), environmental training, environmental auditing and green related research and development. The literature indicates that sustainability is beneficial for the environment, generates cost savings and improves organizational performance, such as enhanced sales revenue and market share $[100,106]$. To that end, a strategic orientation towards sustainability from one company is not enough for that company to be fully sustainable, but an all-encompassing effort is needed. As highlighted by Pero et al. [95], sustainability is not a matter of a single company but a matter of the supply chain. Collaboration between supply chain partners and along the construction stages is necessary for achieving a fully sustainable behavior $[81,99,107]$.

\subsubsection{Organizational Behavior}

This last subject area comprises just one practice, namely 'information and communication technology integration'. Information and communication technology (ICT) delivers an environment within which supply chain members have greater accessibility to one another and can conveniently retrieve or send information at any time and in any place [12,17]. Therefore, it plays a key role to ensure consistent and efficient information management [5] and to enhance communication and coordination within the supply chain [6], [115]. ICT impacts both on technical and managerial sides boosting the effectiveness and efficiency of designing and managing projects [20]. Building information modeling (BIM), an "objectbased and multidisciplinary approach aimed at facilitating collaboration between parties and the integration of object-related information over the entire life cycle of an asset" [42], is one of the most popular and increasingly important technologies [39]. BIM adoption has become a paradigm shift in the construction industry, increasing productivity, reducing failure costs and fostering new ways of collaboration [42,57,59,66,103]. BIM related applications were identified in almost all the previously discussed elements, corroborating the idea that this technology is rapidly transforming the construction industry [49]. Recent trends have been directed towards exploring new ways of capturing and synchronizing real-time information with BIM. This entails integrating BIM with other technologies, such as RFID [59], geographic information systems [19,50,67], web map service [49] and internet of things [61], to improve supply chain transparency, visibility and traceability, thus making supply chains more agile, flexible and resilient. Yet, to take advantage of ICT, consistent adoption of these technologies along the supply chain is required [39]. Considering that the construction supply chain is formed by many small- and medium-sized enterprises, facing the challenge of diffusing these new technologies should be a priority $[20,39,72]$. In particular, issues with costs, compatibility and interoperability, lack of awareness and suppliers' reluctance to adopt needs to be managed [39]. 


\section{Discussion}

A total of 108 articles formed the final sample of this review. The majority was focused on specific topics regarding just one subject area (i.e., $55 \%$ contributed to only one core element and $7 \%$ to more than one core element). Nearly $27 \%$ of the articles contributed to two subject areas and the last $11 \%$ contributed to more than two subject areas. Neither of them concurrently discussed elements included in the five subject areas. This confirms the point made by [26] that most studies focus on specific areas and reinforces the research gap: there is a clear need to present a total solution for SCM in the construction industry. The review of research into core concepts and practices underpinning SCM in the construction industry, as identified through the systematic review procedures, coded into elements and classified into subject areas according to Croom et al.'s [27] framework, produced a comprehensive picture of the current state of knowledge in this area (see Table 1). It integrates different perspectives and contributions made by the extant literature over the years to present a global perspective of SCM in the construction industry. Figure 7 shows the number of articles that contributed to each subject area.

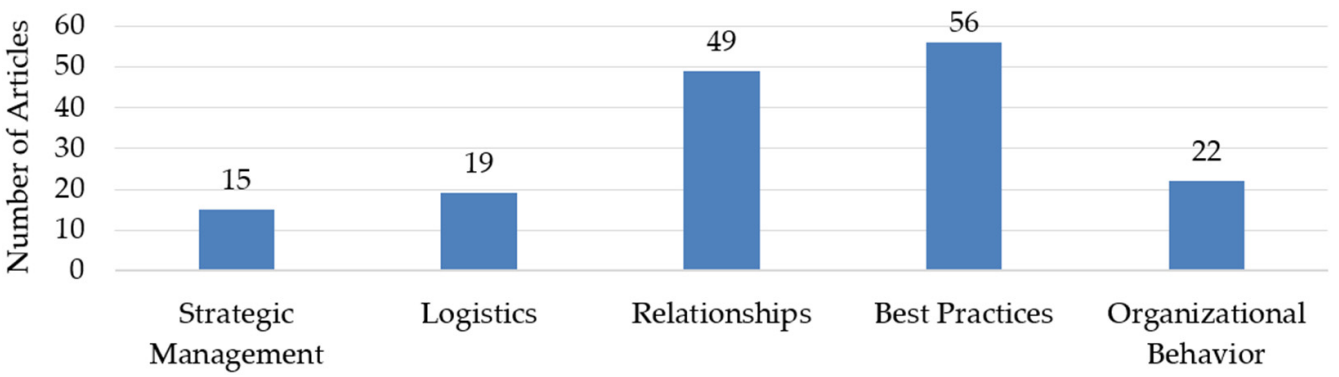

Figure 7. Number of articles that contributed to each subject area. Note: Some articles cover more than one subject area.

The first subject area, strategic management, brought together the elements that promote a strategic orientation toward SCM adoption. The results show that effective implementation of SCM requires defining a strategy that takes a systems approach to view the supply chain as a single entity. Intra-firm and inter-firm capabilities must be synchronized and converge into a unified force in pursuit of customer value [120]. Findings also suggest that this strategic perspective requires firms to have proper capabilities and motivation to embrace change. These insights echo the previous work of Esper et al. [121], who discussed the concept of supply chain orientation as an antecedent to SCM. According to the authors, supply chain-oriented organizations place strategic emphasis on systemic, integrated SCM, and support this emphasis with an organizational structure (e.g., employees with key SCM skills, metrics to facilitate SC alignment and motivation, etc.) that capitalizes on this strategy.

The following subject area, logistics, can be traced back into the origins of SCM and relates to the effective management of materials and information flows [120,122]. The significant representativeness of materials transportation in total costs has spurred scholarly research into this topic. As presented by [123], numerous models to facilitate decisions that play important roles in the planning and control of material flows were identified in the literature. Moreover, findings suggest that the industry has started its own development and experimentation of new technologies intended to enhance real-time integration of material and information flows. These applications, as highlighted by [124], could help to solve many of the shortcomings of traditional logistics and improve construction quality. Coherently with the work of [125], the review also pointed to efficiency potentials in expanding the scope of logistics management beyond the individual construction site to include coordination across supply chains and construction sites. Although such approaches present challenges in terms of more advanced coordination amongst the actors involved, the advancement of new technologies is argued to open up for new ways of organizing the work more efficiently [55]. 
Relationships, associated with the management of the interface relationships within and between various supply chain members, are another key aspect of SCM [122]. As defined by [126], the focus of supply chain management is upon the management of relationships to deliver better customer value at less cost to the supply chain as a whole. This involves recognizing that through cooperation and proper relationship management, the 'whole can be greater than the sum of its parts' [126]. In this direction, the review reveals the grounding elements to change from the traditional adversarial to collaborative supply chain relationships. In other words, our findings suggest that procurement, objectives alignment, top management support and long-term commitment, trust, collaboration, communication, problem solving and risk sharing are the elements laying the foundation for good relationships among the SC members. They provide guidance as antecedents that need to be in place to obtain success in managing relationships. Notwithstanding, evidence suggests that there is no generic approach to pursue supply chain relationship management. This implication is consistent with previous studies of [127,128], who indicated that in order to fully exploit joint opportunities, each relationship has to be managed according to specific circumstances, such as the importance of the partner to the business.

When it comes to best practices, there were five main points of convergence: continuous improvement, lean thinking, offsite manufacturing, just-in-time and sustainability. Notably, due to the increasing sustainability requirements of the industry [2], sustainability has become the most popular research theme. The Council of Supply Chain Management Professionals [129] contends that best practice refers to a process or group of processes recognized as the best method for conducting an action. Best practices are the cause of best performance and provide opportunities for gaining strategic, operational and financial advantages. Accordingly, the identified practices have already attracted numerous research efforts as individual and disjointed supply chain tactics. However, findings also recognize the importance to integrate them with supply chain management. That is, compared to best practices in isolation, best practices are more successful when coordinated over the supply chain. For example, refs. [66,95] demonstrated, respectively, a step-wise improvement of the efficiency of lean practices and sustainability when integrated with supply chain management. Hence, the review not only identified the main best practices addressed by the construction supply chain literature for achieving performance improvement, but also indicates that combining them with supply chain collaboration is essential to foster results.

Finally, information and communication technology integration was the only element identified in the organizational behavior subject area. Being a major driver to improve information sharing, communication and coordination across the multiple SC participants, ICT was deemed as a crucial enabler to supply chain management. A recent report by McKinsey Global Institute [2] urged the widespread adoption of ICT as a way to transform the effectiveness and efficiency of construction. In accordance with [130], the reviewed evidence revealed that the industry is increasingly embracing BIM as the dominant technology, which is acting as a platform for construction innovation and digitization. In particular, [130] showed that BIM, internet of things (IoT) and big data (BD) are the main drivers of the fourth industrial revolution in construction and provide significant benefits, such as improved real-time monitoring, data exchange and construction planning, among others. However, in order to achieve the expected benefits, the results highlighted that the ICT gap between supply chain parties stills needs to be minimized. Hence, this paper reinforces the recent work of [124] about the importance of diffusing ICT technologies, mostly developed by the larger organizations, also among the average construction firms, with low-profit margins and spending power.

\section{Conclusions}

A proper and holistic understanding of context-specific core concepts and practices underpinning SCM is recognized as essential in order to foster its implementation in the construction industry. However, studies continue to focus on very specific fields of research and fail to present a total solution. This paper responded to this research gap by 
conducting a systematic literature review. Following a sophisticated protocol, 108 relevant articles from ISI Web of Science were collected. These articles were analyzed statistically regarding the publication year, journal research area, geographical location and keywords co-occurrence. Going beyond the scope of existing studies, the full range of perspectives and contributions incorporated from distinct fields of research were analyzed to capture the documented core concepts and practices underlying SCM in the construction industry. As a result, a set of 19 core elements were revealed and classified into five different SCM subject areas, namely 'strategic management', 'logistics', 'relationships', 'best practices' and 'organizational behavior'.

This study made significant contributions. It delineated the SCM domain in the construction industry, providing a structured and comprehensive picture of the current state of knowledge. In addition, every revealed core element was discussed in detail, providing some valuable insights about its specific importance and how they are related to the broader SCM field. The review also pointed that the trend goes towards more external collaboration, and highlighted the challenges that need to be addressed. Hence, this study serves as a frame of reference for practitioners and researchers in the field. It has considerable potential to accelerate the understanding and implementation of SCM within the construction industry. In particular, this paper offers some sense of assistance to construction managers in highlighting the core CSCM elements that matter most. While not suggesting a prescriptive step-by-step approach, managers can use the results to identify and prioritize core elements that could be addressed and determine a strategy to enhance the possibilities of the successful implementation of SCM.

Every study has limitations, and this review is certainly no exception. ISI Web of Science was chosen as the only database. Thus, the data coverage might not be all-inclusive, as the consideration of other research databases (e.g., Scopus) could have led to the inclusion of additional articles. Additionally, the research was restricted to peer reviewed articles published in English, leaving aside other sources (e.g., books, conference publications) that are also part of the SCM body of knowledge and documents published in other languages. Finally, the inclusion and exclusion criteria may have inadvertently excluded some important studies.

These limitations could serve as fertile areas for further research. Replications of this research may test and validate with empirical data the proposed findings. Other research directions could include exploring cause-effect relationships between revealed core elements and developing tools to measure elements maturity level. These approaches will support organizations to analyze where improvement is needed and infer priorities to develop strategies to foster SCM implementation.

Author Contributions: W.P.S. and L.C.B.D.B.M. have equally contributed to this study. All authors have read and agreed to the published version of the manuscript.

Funding: This research received no external funding.

Data Availability Statement: The data presented in this study are available on request from the corresponding authors.

Conflicts of Interest: The authors declare no conflict of interest.

\section{References}

1. Xue, X.; Li, X.; Shen, Q.; Wang, Y. An agent-based framework for supply chain coordination in construction. Autom. Constr. 2005, 14, 413-430. [CrossRef]

2. McKinsey Global Institute. Reinventing Construction: A Route to Higher Productivity; McKinsey \& Company: Chicago, IL, USA, 2017.

3. Yeo, K.; Ning, J. Managing uncertainty in major equipment procurement in engineering projects. Eur. J. Oper. Res. 2006, 171, 123-134. [CrossRef]

4. Durdyev, S.; Ismail, S. Offsite manufacturing in the construction industry for productivity improvement. Eng. Manag. J. 2019, 31, 35-46. [CrossRef]

5. Lönngren, H.; Rosenkranz, C.; Kolbe, H. Aggregated construction supply chains: Success factors in implementation of strategic partnerships. Supply Chain Manag. Int. J. 2010, 15, 404-411. [CrossRef] 
6. Fulford, R.; Standing, C. Construction industry productivity and the potential for collaborative practice. Int. J. Proj. Manag. 2014, 32, 315-326. [CrossRef]

7. Costa, F.; Granja, A.D.; Fregola, A.; Picchi, F.; Staudacher, A.P. Understanding relative importance of barriers to improving the customer-supplier relationship within construction supply chains using DEMATEL technique. J. Manag. Eng. 2019, 35, 04019002. [CrossRef]

8. Tah, J.H. Towards an agent-based construction supply network modelling and simulation platform. Autom. Constr. 2005, 14, 353-359. [CrossRef]

9. Behera, P.; Mohanty, R.; Prakash, A. Understanding construction supply chain management. Prod. Plan. Control. 2015, 26, 1332-1350. [CrossRef]

10. Kim, S.-Y.; Nguyen, V.T. A structural model for the impact of supply chain relationship traits on project performance in construction. Prod. Plan. Control. 2018, 29, 170-183. [CrossRef]

11. Broft, R.D.; Badi, S.M.; Pryke, S. Towards supply chain maturity in construction. Built Environ. Proj. Asset Manag. 2016, 6, 187-204. [CrossRef]

12. Abedi, M.; Fathi, M.; Mirasa, A.; Rawai, N. Integrated collaborative tools for precast supply chain management. Sci. Iran. 2016, 23, 429-448. [CrossRef]

13. Bankvall, L.; Bygballe, L.E.; Dubois, A.; Jahre, M. Interdependence in supply chains and projects in construction. Supply Chain Manag. Int. J. 2010, 15, 385-393. [CrossRef]

14. Briscoe, G.; Dainty, A. Construction supply chain integration: An elusive goal? Supply Chain Manag. Int. J. 2005, 10, 319-326. [CrossRef]

15. Eriksson, P.E. Improving construction supply chain collaboration and performance: A lean construction pilot project. Supply Chain Manag. Int. J. 2010, 15, 394-403. [CrossRef]

16. Adetunji, I.; Price, A.D.F.; Fleming, P. Achieving sustainability in the construction supply chain. Proc. Inst. Civ. Eng. Eng. Sustain. 2008, 161, 161-172. [CrossRef]

17. Love, P.E.D.; Irani, Z.; Edwards, D.J. A seamless supply chain management model for construction. Supply Chain Manag. 2004, 9, 43-56. [CrossRef]

18. Meng, X.; Sun, M.; Jones, M. Maturity model for supply chain relationships in construction. J. Manag. Eng. 2011, 27, 97-105. [CrossRef]

19. Irizarry, J.; Karan, E.P.; Jalaei, F. Integrating BIM and GIS to improve the visual monitoring of construction supply chain management. Autom. Constr. 2013, 31, 241-254. [CrossRef]

20. Aloini, D.; Dulmin, R.; Mininno, V.; Ponticelli, S. Key antecedents and practices for Supply Chain Management adoption in project contexts. Int. J. Proj. Manag. 2015, 33, 1301-1316. [CrossRef]

21. Young, D.A.; Haas, C.T.; Goodrum, P.; Caldas, C. Improving construction supply network visibility by using automated materials locating and tracking technology. J. Constr. Eng. Manag. 2011, 137, 976-984. [CrossRef]

22. Xue, X.; Wang, Y.; Shen, Q.; Yu, X. Coordination mechanisms for construction supply chain management in the Internet environment. Int. J. Proj. Manag. 2007, 25, 150-157. [CrossRef]

23. Arantes, A.; Ferreira, L.; Costa, A.A. Is the construction industry aware of supply chain management? The Portuguese contractors' perspective. Supply Chain Manag. Int. J. 2015, 20, 404-414. [CrossRef]

24. Shishodia, A.; Verma, P.; Dixit, V. Supplier evaluation for resilient project driven supply chain. Comput. Ind. Eng. 2019, 129, 465-478. [CrossRef]

25. Dallasega, P.; Rojas, R.A.; Bruno, G.; Rauch, E. An agile scheduling and control approach in ETO construction supply chains. Comput. Ind. 2019, 112, 103122. [CrossRef]

26. Tiwari, R.; Shepherd, H.; Pandey, R.K. Supply chain management in construction: A literature survey. Int. J. Manag. Res. Bus. Strateg. 2014, 3, 7-28.

27. Croom, S.; Romano, P.; Giannakis, M. Supply chain management: An analytical framework for critical literature review. Eur. J. Purch. Supply Manag. 2000, 6, 67-83. [CrossRef]

28. Isatto, E.L.; Azambuja, M.; Formoso, C.T. The role of commitments in the management of construction make-to-order supply chains. J. Manag. Eng. 2015, 31, 04014053. [CrossRef]

29. Terregino, C.; Toffan, A.; Cilloni, F.; Monne, I.; Bertoli, E.; Castellanos, L.; Amarin, N.; Mancin, M.; Capua, I. Evaluation of the protection induced by avian influenza vaccines containing a 1994 Mexican H5N2 LPAI seed strain against a 2008 Egyptian H5N1 HPAI virus belonging to clade 2.2.1 by means of serological and in vivo tests. Avian Pathol. 2010, 39, 215-222. [CrossRef] [PubMed]

30. Durach, C.F.; Kembro, J.; Wieland, A. A new paradigm for systematic literature reviews in supply chain management. J. Supply Chain Manag. 2017, 53, 67-85. [CrossRef]

31. Thomé, A.M.T.; Scavarda, L.F.; Scavarda, A.J. Conducting systematic literature review in operations management. Prod. Plan. Control. 2016, 27, 408-420. [CrossRef]

32. Tranfield, D.; Denyer, D.; Smart, P. Towards a methodology for developing evidence-informed management knowledge by means of systematic review. Br. J. Manag. 2003, 14, 207-222. [CrossRef]

33. Moher, D.; Liberati, A.; Tetzlaff, J.; Altman, D.G. Preferred Reporting Items for Systematic Reviews and Meta-Analyses: The PRISMA Statement. PLoS Med. 2009, 6, e1000097. [CrossRef] [PubMed] 
34. Su, H.-N.; Lee, P.-C. Mapping knowledge structure by keyword co-occurrence: A first look at journal papers in Technology Foresight. Scientometrics 2010, 85, 65-79. [CrossRef]

35. Jin, R.; Zou, Y.; Gidado, K.; Ashton, P.; Painting, N. Scientometric analysis of BIM-based research in construction engineering and management. Eng. Constr. Arch. Manag. 2019, 26, 1750-1776. [CrossRef]

36. Costantino, N.; Dotoli, M.; Falagario, M.; Fanti, M.P.; Iacobellis, G. A decision support system framework for purchasing management in supply chains. J. Bus. Ind. Mark. 2009, 24, 278-290. [CrossRef]

37. Cheng, J.C.; Law, K.H.; Bjornsson, H.; Jones, A.; Sriram, R.D. Modeling and monitoring of construction supply chains. Adv. Eng. Inform. 2010, 24, 435-455. [CrossRef]

38. Meng, X. Proactive management in the context of construction supply chains. Prod. Plan. Control. 2019, 31, 527-539. [CrossRef]

39. Pala, M.; Edum-Fotwe, F.; Ruikar, K.; Doughty, N.; Peters, C. Contractor practices for managing extended supply chain tiers. Supply Chain Manag. Int. J. 2014, 19, 31-45. [CrossRef]

40. Chileshe, N.; Rameezdeen, R.; Hosseini, M.R.; Lehmann, S. Barriers to implementing reverse logistics in South Australian construction organisations. Supply Chain Manag. Int. J. 2015, 20, 179-204. [CrossRef]

41. Childerhouse, P.; Lewis, J.; Naim, M.; Towill, D.R. Re-engineering a construction supply chain: A material flow control approach Supply Chain Manag. Int. J. 2003, 8, 395-406. [CrossRef]

42. Siebelink, S.; Voordijk, J.T.; Adriaanse, A. Developing and testing a tool to evaluate BIM maturity: Sectoral analysis in the Dutch construction industry. J. Constr. Eng. Manag. 2018, 144, 05018007. [CrossRef]

43. Upstill-Goddard, J.; Glass, J.; Dainty, A.; Nicholson, I. Implementing sustainability in small and medium-sized construction firms. Eng. Constr. Arch. Manag. 2016, 23, 407-427. [CrossRef]

44. Rudolf, C.A.; Spinler, S. Key risks in the supply chain of large scale engineering and construction projects. Supply Chain Manag. Int. J. 2018, 23, 336-350. [CrossRef]

45. Balasubramanian, S.; Shukla, V. Green supply chain management: An empirical investigation on the construction sector. Supply Chain Manag. Int. J. 2017, 22, 58-81. [CrossRef]

46. Balasubramanian, S.; Shukla, V. Environmental supply chain management in the construction sector: Theoretical underpinnings. Int. J. Logist. Res. Appl. 2018, 21, 502-528. [CrossRef]

47. Vidalakis, C.; Tookey, E.J.; Sommerville, J. Demand uncertainty in construction supply chains: A discrete event simulation study. J. Oper. Res. Soc. 2013, 64, 1194-1204. [CrossRef]

48. Meng, J.; Yan, J.; Xue, B.; Fu, J.; He, N. Reducing construction material cost by optimizing buy-in decision that accounts the flexibility of non-critical activities. Eng. Constr. Arch. Manag. 2018, 25, 1092-1108. [CrossRef]

49. Chen, P.-H.; Nguyen, T.C. A BIM-WMS integrated decision support tool for supply chain management in construction. Autom. Constr. 2019, 98, 289-301. [CrossRef]

50. Deng, Y.; Gan, V.J.L.; Das, M.; Cheng, J.C.P.; Anumba, C. Integrating 4D BIM and GIS for construction supply chain management. J. Constr. Eng. Manag. 2019, 145, 04019016. [CrossRef]

51. Hsu, P.-Y.; Aurisicchio, M.; Angeloudis, P. Risk-averse supply chain for modular construction projects. Autom. Constr. 2019, 106, 102898. [CrossRef]

52. Ahmadian, F.F.A.; Akbarnezhad, A.; Rashidi, T.H.; Waller, S.T. Accounting for transport times in planning off-site shipment of construction materials. J. Constr. Eng. Manag. 2016, 142, 04015050. [CrossRef]

53. Jaśkowski, P.; Sobotka, A.; Czarnigowska, A. Decision model for selecting supply sources of road construction aggregates. Eng. Econ. 2014, 25, 13-20. [CrossRef]

54. Liu, J.; Lu, M. Constraint programming approach to optimizing project schedules under material logistics and crew availability constraints. J. Constr. Eng. Manag. 2018, 144, 04018049. [CrossRef]

55. Dubois, A.; Hulthén, K.; Sundquist, V. Organising logistics and transport activities in construction. Int. J. Logist. Manag. 2019, 30, 620-640. [CrossRef]

56. Ala-Risku, T.; Kärkkäinen, M. Material delivery problems in construction projects: A possible solution. Int. J. Prod. Econ. 2006, 104, 19-29. [CrossRef]

57. Babič, N.Č.; Rebolj, D.; Nekrep-Perc, M.; Podbreznik, P. Supply-chain transparency within industrialized construction projects. Comput. Ind. 2014, 65, 345-353. [CrossRef]

58. Hinkka, V.; Tätilä, J. RFID tracking implementation model for the technical trade and construction supply chains. Autom. Constr. 2013, 35, 405-414. [CrossRef]

59. Lu, W.; Huang, G.Q.; Li, H. Scenarios for applying RFID technology in construction project management. Autom. Constr. 2011, 20, 101-106. [CrossRef]

60. Chen, J.; Fang, Y.; Cho, Y.K.; Kim, C. Principal axes descriptor for automated construction-equipment classification from point clouds. J. Comput. Civ. Eng. 2017, 31, 04016058. [CrossRef]

61. Niu, Y.; Lu, W.; Liu, D.; Chen, K.; Anumba, C.; Huang, G.G. An SCO-enabled logistics and supply chain-management system in construction. J. Constr. Eng. Manag. 2017, 143, 04016103. [CrossRef]

62. Shahvand, E.; Sebt, M.H.; Banki, M.T. Developing fuzzy expert system for supplier and subcontractor evaluation in construction industry. Sci. Iran. 2016, 23, 842-855. [CrossRef]

63. Kayhan, B.M.; Cebi, S.; Kahraman, C. Determining and prioritizing main factors of supplier reliability in construction industry. J. Mult. Log. Soft Comput. 2019, 32, 111-134. 
64. Matić, B.; Jovanović, S.; Das, D.K.; Zavadskas, E.K.; Stević, Ž.; Sremac, S.; Marinković, M. A new hybrid MCDM model: Sustainable supplier selection in a construction company. Symmetry 2019, 11, 353. [CrossRef]

65. Azambuja, M.M.; Ponticelli, S.; O’Brien, W.J. Strategic procurement practices for the industrial supply chain. J. Constr. Eng. Manag. 2014, 140, 06014005. [CrossRef]

66. Meng, X. Lean management in the context of construction supply chains. Int. J. Prod. Res. 2019, 57, 3784-3798. [CrossRef]

67. Wang, T.-K.; Zhang, Q.; Chong, H.-Y.; Wang, X. Integrated supplier selection framework in a resilient construction supply chain: An approach via Analytic Hierarchy Process (AHP) and Grey Relational Analysis (GRA). Sustainability 2017, 9, 289. [CrossRef]

68. Ilie-Zudor, E.; Monostori, L. Agent-based framework for pre-contractual evaluation of participants in project-delivery supplychains. Assem. Autom. 2009, 29, 137-153. [CrossRef]

69. Liang, R.; Chong, H.-Y. A hybrid group decision model for green supplier selection: A case study of megaprojects. Eng. Constr. Arch. Manag. 2019, 26, 1712-1734. [CrossRef]

70. Bohari, A.A.M.; Skitmore, M.; Xia, B.; Teo, M. Green oriented procurement for building projects: Preliminary findings from Malaysia. J. Clean. Prod. 2017, 148, 690-700. [CrossRef]

71. Li, Y.; He, N.; Li, H.; Liu, Z.; Qi, J. Influencing factors on inter-organizational trust asymmetry behavior in construction projects. Eng. Constr. Arch. Manag. 2019, 28, 308-331. [CrossRef]

72. Chalker, M.; Loosemore, M. Trust and productivity in Australian construction projects: A subcontractor perspective. Eng. Constr. Arch. Manag. 2016, 23, 192-210. [CrossRef]

73. Khalfan, M.; McDermott, P.; Swan, W. Building trust in construction projects. Supply Chain Manag. Int. J. 2007, 12, 385-391. [CrossRef]

74. Hao, C.; Du, Q.; Huang, Y.; Shao, L.; Yan, Y. Evolutionary game analysis on knowledge-sharing behavior in the construction supply chain. Sustainability 2019, 11, 5319. [CrossRef]

75. Arbulu, R.; Tommelein, I.; Walsh, K.; Hershauer, J. Value stream analysis of a re-engineered construction supply chain. Build. Res. Inf. 2003, 31, 161-171. [CrossRef]

76. Xie, C.; Wu, D.; Luo, J.; Hu, X. A case study of multi-team communications in construction design under supply chain partnering. Supply Chain Manag. Int. J. 2010, 15, 363-370. [CrossRef]

77. Ireland, P. Managing appropriately in construction power regimes: Understanding the impact of regularity in the project environment. Supply Chain Manag. Int. J. 2004, 9, 372-382. [CrossRef]

78. Aaltonen, K.; Turkulainen, V. Creating relational capital through socialization in project alliances. Int. J. Oper. Prod. Manag. 2018, 38, 1387-1421. [CrossRef]

79. Vallet-Bellmunt, T.; Rivera-Torres, P. Integration: Attitudes, patterns and practices. Supply Chain Manag. Int. J. 2013, 18, 308-323. [CrossRef]

80. Vicedo, J.C.; Mula, J.; Capó, J. A social network-based organizational model for improving knowledge management in supply chains. Supply Chain Manag. Int. J. 2011, 16, 379-388. [CrossRef]

81. Woo, C.; Kim, M.G.; Chung, Y.; Rho, J.J. Suppliers' communication capability and external green integration for green and financial performance in Korean construction industry. J. Clean. Prod. 2016, 112, 483-493. [CrossRef]

82. Wang, Q.; Shi, Q. The incentive mechanism of knowledge sharing in the industrial construction supply chain based on a supervisory mechanism. Eng. Constr. Arch. Manag. 2019, 26, 989-1003. [CrossRef]

83. Quang, H.T.; Hara, Y. Risks and performance in supply chain: The push effect. Int. J. Prod. Res. 2018, 56, 1369-1388. [CrossRef]

84. Truong, H.Q.; Hara, Y. Supply chain risk management: Manufacturing- and service-oriented firms. J. Manuf. Technol. Manag. 2018, 29, 218-239. [CrossRef]

85. Naderpajouh, N.; Hastak, M.; Gokhale, S.; Bayraktar, M.E.; Iyer, A.; Arif, F. Counterfeiting risk governance in the capital projects supply chain. J. Constr. Eng. Manag. 2015, 141, 04014084. [CrossRef]

86. Shojaei, P.; Haeri, S.A.S. Development of supply chain risk management approaches for construction projects: A grounded theory approach. Comput. Ind. Eng. 2019, 128, 837-850. [CrossRef]

87. Halman, J.I.M.; Voordijk, J.T. Balanced framework for measuring performance of supply chains in house building. J. Constr. Eng. Manag. 2012, 138, 1444-1450. [CrossRef]

88. Wickramatillake, C.D.; Koh, S.L.; Gunasekaran, A.; Arunachalam, S. Measuring performance within the supply chain of a large scale project. Supply Chain Manag. Int. J. 2007, 12, 52-59. [CrossRef]

89. Zeng, W.; Wang, H.; Li, H.; Zhou, H.; Wu, P.; Le, Y. Incentive mechanisms for supplier development in mega construction projects IEEE Trans. Eng. Manag. 2019, 66, 252-265. [CrossRef]

90. Bajjou, M.S.; Chafi, A. Identifying and managing critical waste factors for lean construction projects. Eng. Manag. J. 2020, 32, 2-13. [CrossRef]

91. Tezel, A.; Koskela, L.; Aziz, Z. Current condition and future directions for lean construction in highways projects: A small and medium-sized enterprises (SMEs) perspective. Int. J. Proj. Manag. 2018, 36, 267-286. [CrossRef]

92. Dallasega, P.; Rauch, E. Sustainable construction supply chains through synchronized production planning and control in engineer-to-order enterprises. Sustainability 2017, 9, 1888. [CrossRef]

93. Kong, L.; Li, H.; Luo, H.; Ding, L.; Zhang, X. Sustainable performance of just-in-time (JIT) management in time-dependent batch delivery scheduling of precast construction. J. Clean. Prod. 2018, 193, 684-701. [CrossRef] 
94. Lee, J.; Park, M.; Lee, H.-S.; Hyun, H. Classification of modular building construction projects based on schedule-driven approach. J. Constr. Eng. Manag. 2019, 145, 04019031. [CrossRef]

95. Pero, M.; Moretto, A.; Bottani, E.; Bigliardi, B. Environmental collaboration for sustainability in the construction industry: An exploratory study in Italy. Sustainability 2017, 9, 125. [CrossRef]

96. Martinez, S.; Delgado, M.D.M.; Marin, R.M.; Alvarez, S. Organization environmental footprint through input-output analysis: A case study in the construction sector. J. Ind. Ecol. 2018, 23, 879-892. [CrossRef]

97. Hsueh, S.-L.; Yan, M.-R. A multimethodology contractor assessment model for facilitating green innovation: The view of energy and environmental protection. Sci. World J. 2013, 2013, 1-14. [CrossRef]

98. Wong, J.K.W.; Chan, J.K.S.; Wadu, M.J. Facilitating effective green procurement in construction projects: An empirical study of the enablers. J. Clean. Prod. 2016, 135, 859-871. [CrossRef]

99. Zhang, J.; Qi, X.; Liang, C. Tackling complexity in green contractor selection for mega infrastructure projects: A hesitant fuzzy linguistic MADM approach with considering group attitudinal character and attributes' interdependency. Complexity 2018, 2018, 1-31. [CrossRef]

100. Li, Y.; Ding, R.; Sun, T. The drivers and performance of environmental practices in the Chinese construction industry. Sustainability 2019, 11, 614. [CrossRef]

101. Shen, L.; Zhang, Z.; Zhang, X. Key factors affecting green procurement in real estate development: A China study. J. Clean. Prod. 2017, 153, 372-383. [CrossRef]

102. Freitas, L.A.R.U.; Magrini, A. Waste management in industrial construction: Investigating contributions from industrial ecology. Sustainability 2017, 9, 1251. [CrossRef]

103. Akinade, O.O.; Oyedele, L.O. Integrating construction supply chains within a circular economy: An ANFIS-based waste analytics system (A-WAS). J. Clean. Prod. 2019, 229, 863-873. [CrossRef]

104. Chileshe, N.; Rameezdeen, R.; Hosseini, M.R.; Lehmann, S.; Udeaja, C. Analysis of reverse logistics implementation practices by South Australian construction organisations. Int. J. Oper. Prod. Manag. 2016, 36, 332-356. [CrossRef]

105. Chileshe, N.; Jayasinghe, R.S.; Rameezdeen, R. Information flow-centric approach for reverse logistics supply chains. Autom. Constr. 2019, 106, 102858. [CrossRef]

106. Balasubramanian, S.; Shukla, V. Green supply chain management: The case of the construction sector in the United Arab Emirates (UAE). Prod. Plan. Control. 2017, 28, 1116-1138. [CrossRef]

107. Albino, V.; Berardi, U. Green buildings and organizational changes in Italian case studies. Bus. Strat. Environ. 2012, 21, 387-400. [CrossRef]

108. Ahmadian, F.F.A.; Rashidi, T.H.; Akbarnezhad, A.; Waller, S.T. BIM-enabled sustainability assessment of material supply decisions. Eng. Constr. Arch. Manag. 2017, 24, 668-695. [CrossRef]

109. da Rocha, C.G.; Sattler, M.A. A discussion on the reuse of building components in Brazil: An analysis of major social, economical and legal factors. Resour. Conserv. Recycl. 2009, 54, 104-112. [CrossRef]

110. Nasir, M.H.A.; Genovese, A.; Acquaye, A.; Koh, S.; Yamoah, F. Comparing linear and circular supply chains: A case study from the construction industry. Int. J. Prod. Econ. 2017, 183, 443-457. [CrossRef]

111. Chileshe, N.; Rameezdeen, R.; Hosseini, M.R. Drivers for adopting reverse logistics in the construction industry: A qualitative study. Eng. Constr. Arch. Manag. 2016, 23, 134-157. [CrossRef]

112. Warren, J.D.; Chong, W.K.O.; Kim, C. Recycling construction and demolition waste for construction in Kansas City Metropolitan Area, Kansas and Missouri. Transp. Res. Rec. J. Transp. Res. Board 2007, 2011, 193-200. [CrossRef]

113. Ma, L.; Wang, L.; Skibniewski, M.J.; Gajda, W. An eco-innovative framework development for sustainable consumption and production in the construction industry. Technol. Econ. Dev. Econ. 2019, 25, 774-801. [CrossRef]

114. Xu, J.; Shi, Y.; Zhao, S. Reverse logistics network-based multiperiod optimization for construction and demolition waste disposal. J. Constr. Eng. Manag. 2019, 145, 04018124. [CrossRef]

115. Tserng, H.P.; Dzeng, R.-J.; Lin, Y.-C.; Lin, S.-T. Mobile construction supply chain management using PDA and bar codes. Comput. Civ. Infrastruct. Eng. 2005, 20, 242-264. [CrossRef]

116. Costa, A.A.; Tavares, L.V. Social e-business and the Satellite Network model: Innovative concepts to improve collaboration in construction. Autom. Constr. 2012, 22, 387-397. [CrossRef]

117. Wang, L.-C.; Lin, Y.-C.; Lin, P.H. Dynamic mobile RFID-based supply chain control and management system in construction. Adv. Eng. Inform. 2007, 21, 377-390. [CrossRef]

118. Gadde, L.-E.; Dubois, A. Partnering in the construction industry-Problems and opportunities. J. Purch. Supply Manag. 2010, 16, 254-263. [CrossRef]

119. Lean Enterprise Institute. What Is Lean? Available online: https://www.lean.org/whatslean/ (accessed on 30 May 2021).

120. Mentzer, J.T.; DeWitt, W.; Keebler, J.S.; Min, S.; Nix, N.W.; Smith, C.D.; Zacharia, Z.G. Defining supply chain management. J. Bus. Logist. 2001, 22, 1-25. [CrossRef]

121. Esper, T.L.; Defee, C.C.; Mentzer, J.T. A framework of supply chain orientation. Int. J. Logist. Manag. 2010, 21, 161-179. [CrossRef]

122. Stock, J.R.; Boyer, S.L.; Harmon, T. Research opportunities in supply chain management. J. Acad. Mark. Sci. 2010, 38, 32-41. [CrossRef]

123. Sarker, B.R.; Egbelu, P.J.; Liao, T.W.; Yu, J. Planning and design models for construction industry: A critical survey. Autom. Constr. 2012, 22, 123-134. [CrossRef] 
124. Jelodar, M.B.; Shu, F. Innovative use of low-cost digitisation for smart information systems in construction projects. Buildings 2021, 11, 270. [CrossRef]

125. El Moussaoui, S.; Lafhaj, Z.; Leite, F.; Fléchard, J.; Linéatte, B. Construction logistics centres proposing kitting service: Organization analysis and cost mapping. Buildings 2021, 11, 105. [CrossRef]

126. Christopher, M. Logistics and Supply Chain Management: Creating Value-Adding Networks, 4th ed.; Financial Times Prentice Hall: Harlow, UK, 2011.

127. Cox, A.; Ireland, P. Managing construction supply chain: The common sense approach. Eng. Constr. Archit. Manag. 2002, 9, 409-416. [CrossRef]

128. Bemelmans, J.; Voordijk, H.; Vos, B.; Buter, J. Assessing buyer-supplier relationship management: Multiple case-study in the Dutch construction industry. J. Constr. Eng. Manag. 2012, 138, 163-176. [CrossRef]

129. CSCMP. Supply Chain Management: Terms and Glossary. Available online: https://cscmp.org/CSCMP/Academia/SCM_ Definitions_and_Glossary_of_Terms (accessed on 7 September 2021).

130. Begić, H.; Galić, M. A systematic review of construction 4.0 in the context of the BIM 4.0 premise. Buildings 2021, $11,337$. [CrossRef] 